Memorias del VII Encuentro Nacional de Experiencias en la Enseñanza de la Biologia y la Educación Ambiental y II Congreso Nacional de Investigación en la Enseñanza de la Biología

\title{
LAS PERCEPCIONES DE LOS NIÑOS DE PRIMARIA ACERCA DE LAS ESPECIES CARISMATICAS Y NO CARISMATICAS
}

\author{
Ángela Becerra Niño ${ }^{1}$ \\ Wilson Valderrama Hurtado ${ }^{2}$ \\ Nidia Torres Merchán ${ }^{3}$
}

\section{Resumen}

Este trabajo hace parte de un proyecto más amplio llamado denominado: "Evaluación de la popularidad de especies carismáticas y no carismáticas en niños de primaria. Contribuciones a la Educación ambiental para la biodiversidad"; tiene como objetivo principal contrastar el grado de popularidad de los niños de cuarto y quinto grado de primaria de instituciones rurales y urbanas, hacia grupos de animales carismáticos y no carismáticos; por ello, en este escrito se presenta los resultados de la prueba piloto realizada con los estudiantes de cuarto grado de primaria del colegio INEM Carlos Arturo Torres de la ciudad de Tunja; en relación con la visión que tienen los estudiantes hacia estas especies.

Palabras clave: Especies carismáticas y no carismáticas, percepciones, Biodiversidad.

\begin{abstract}
This work is part of a larger project called: "Evaluation of the popularity of charismatic and non-charismatic in elementary school children. Contributions to Environmental Education for Biodiversity". The main objective is to compare the degree of popularity of children in fourth and fifth grade to groups and noncharismatic charismatic animals, so in this paper we present the results of the pilot test with the students of fourth grade school INEM Carlos Arturo Torres of the city of Tunja, in relation to the views held by students toward these species.
\end{abstract}

Keywords: charismatic and non-charismatic species, perceptions, Biodiversity.

\section{Introducción}

Es ampliamente documentado como las actuaciones humanas ejercen una presión negativa sobre la Diversidad Biológica, a través de distintos factores causales que involucran desde la pérdida del hábitat hasta el efecto del cambio climático; se han desarrollado distintas líneas de trabajo con el fin de preservar la

\footnotetext{
${ }^{1}$ Semilleros de investigación Grupo de investigación WAIRA. Ambiente, comunidad y Desarrollo.

2 Docente Facultad de Ciencias de la Educación. Universidad Pedagógica y Tecnológica de Colombia.

${ }^{3}$ Facultad de Educación. Universidad Pedagógica y Tecnológica de Colombia. nidia.torres@uptc.edu.co
} 
Bio-grafia Escritos sobre la Biología y su Enseñanza.

Edición Extra-Ordinaria. ISSN 2027-1034 P. p 361-367

Memorias del VII Encuentro Nacional de Experiencias en la Enseñanza de la

Biologia y la Educación Ambiental y II Congreso Nacional de Investigación en la Enseñanza de la Biología

diversidad biológica. Sin embargo, es poco usual la inclusión del componente social, y los estudios que evidencien las percepciones de niños y niñas sobre especies carismáticas y no carismáticas.

De acuerdo a Dunn (2005), la dinámica de las investigaciones para la conservación ha estado direccionada hacia especies de vertebrados y pocas investigaciones se han efectuado frente a la conservación de los invertebrados, a pesar de que se ha demostrado su importancia funcional en los ecosistemas.

El establecimiento de estrategias de conservación requiere partir de conocimientos previos, por ello, se hace necesario abordar las percepciones de los estudiantes, de acuerdo a Murillo \& Trujillo (2010), el concepto percepción, se refiere a la acción o efecto de recibir por uno de los sentidos las imágenes, impresiones o sensaciones externas, o comprender y conocer algo. Las percepciones hacen referencia a un conocimiento, idea o la sensación interior resultante de una impresión hecha en nuestros sentidos, desde este referente se intentara comprender y conocer la preferencia de los estudiantes por animales carismáticos o no carismáticos.

En este sentido, estudios en el campo de la educación, con trabajos de Carrillo (2000), Covas ( 2004) manifiestan que la educación como proceso y la escuela como institución, juegan un papel esencial en reflexiones conscientes acerca de la utilidad que damos actualmente a la naturaleza, por lo que se deben involucrar a todos los miembros de la sociedad en la búsqueda de soluciones para resolver los problemas del ambiente; en este sentido se justifica la participación de los más pequeños en estudios relacionados con el cuidado del ambiente y la conservación de la biodiversidad.

A pesar de que se tienen reconocidas un número de especies, es importante involucrar a los estudiantes desde edades tempranas, para que se motiven hacia el estudios de los insectos; esto no solo contribuye a la alfabetización científica enmarcada en una de las metas de la Unesco 2008, sino que puede contribuir hacia el incremento de actitudes favorables hacia el cuidado del ambiente, con un direccionamiento de conciencia social en futuras generaciones.

Por ello, los grupos carismáticos de animales y las plantas juegan un rol crítico en el nexo entre la ciencia del medio ambiente y la acción ambiental Fleishman y Murphy (2009). En estos grupos se encuentran principalmente animales que son atractivos para el público en sentido estético como los mamíferos, aves y anfibios. De acuerdo a Verissimo et al (2010) las especies emblemáticas carismáticas sirven como símbolos y puntos de reunión para fomentar la sensibilización y acciones de conservación que capturan la imaginación del público e inducen a apoyar las acciones de conservación. 
Memorias del VII Encuentro Nacional de Experiencias en la Enseñanza de la Biología y la Educación Ambiental y II Congreso Nacional de Investigación en la Enseñanza de la Biología

Por otro lado, las percepciones de los insectos varían ampliamente, pero una actitud predominante es que por lo general son asumidos como plagas que deben ser erradicados y no conservados. (Tim R. New; 2011). Estos discernimientos acerca de los insectos imposibilitan el apoyo de la sociedad hacia programas de conservación de insectos.

\section{Metodología}

La implementación de la prueba piloto se realizó en el colegio INEN de Tunja con 36 niños del grado cuarto de primaria con edades de 8 a 11 años. El 52\% son niñas y $48 \%$ son niños.

La resolución de los cuestionarios de caracterización de percepciones sobre especies carismáticas y no carismáticos, en principio se efectuó desde preguntas abiertas y de opción múltiple; luego se aplicó un cuestionario estilo Likert para valorar el grado de identificación y espontaneidad de los niños y grado de aprecio respecto al individuo y valorar si los animales son agradables o desagradables, por ello se realizó además una presentación en Power Point con dos especies de cada grupo representativo y se valoró el grado de apreciación.

\section{Resultados Y Discusión}

En relación a los datos obtenidos en una de las preguntas del cuestionario de indagación: ¿Cuáles son los animales que más te gustan y por qué? Se observó que 16 estudiantes de cuarto grado de primaria prefieren animales domésticos; 14 señalan animales silvestres como preferencia y solo un estudiante menciona su predilección por los insectos.

Es notorio que los niños de $4^{\circ}$ de primaria tienen preferencias por los animales domésticos como el perro, el gato y el conejo entre otros, por tenerlos como mascotas y los caracterizan como amigables, tiernos y juguetones; según Snaddon y Turner (2008) el entorno en el que viven los niños puede influir en sus percepciones, donde la familiaridad y la estética son factores importantes que rigen las conexiones de los niños con los animales. Solo una minoría señala que prefiere a los animales silvestres tales como el león o el tigre destacándolos por su fuerza; pero estos niños solo los conocen por medios de comunicación como la televisión o el internet. Por otro lado cabe destacar que solo un estudiante tuvo preferencia por los insectos (mariposa). De acuerdo a New, TR (2011) las mariposas son aceptados como conocidos y populares por sus colores llamativos, y por reconocer en algunos casos su importancia en la polinización.

Otra de las preguntas propuesta en el cuestionario de indagación cuestionaba:

¿Que animales son los más importantes en la naturaleza? 
Memorias del VII Encuentro Nacional de Experiencias en la Enseñanza de la Biologia y la Educación Ambiental y II Congreso Nacional de Investigación en la Enseñanza de la Biología

Se observa que un $58.1 \%$ de los estudiantes de $4^{\circ}$ señalan que los animales domésticos como las vacas o gallinas son los más importantes en la naturaleza, porque producen alimentos necesarios para vivir como leche, carne, huevos, etc. El 29\% señala animales silvestres como el cóndor, el elefante, el tigre, entre otros; de acuerdo Fleishman y Murphy (2009) por su sentido estético y porque son centinelas del estatus y las tendencias ambientales. En un último 12.9\% mencionan los insectos como abejas, mariposas, mayitas; por cumplir un papel funcional en los ecosistemas terrestres y acuáticos.

Los datos anteriores develan el desconocimiento de la importancia de los insectos en la naturaleza, se observa además que los animales más grandes o llamativos especialmente por su belleza son los más populares por los niños participantes. De los taxones vinculados al desarrollo del cuestionario de indagación, los artrópodos son los menos conocidos; además se observó que grupos como arácnidos y quilópodos fueron clasificados como insectos.

Otra pregunta estaba dirigida a cuestionar sobre que animales están en peligro de desaparecer. Los niños(as) respondieron mayoritariamente que vertebrados como el mono, el oso polar, el delfín rosado, el cóndor, los peces y otros; se encuentran en peligro de extinción; sin embargo, la palabra extinción no tiene un significado claro por los participantes, por lo que se debió cambio por "en peligro de extinción". En esta pregunta unos pocos respondieron que artrópodos como moscos, arañas y hormigas son animales que se encuentran en peligro de extinción. Además a la pregunta ¿Qué podemos hacer para que los animales no se extingan? La mayoría de los educandos respondió en favor del cuidado de la naturaleza y las especies que habitan en ella. De lo anterior, se percibe que los niños de $4^{\circ}$ de primaria son una población importante para la implementación de estrategias de conservación frente a la naturaleza y una posibilidad de fomentar escenarios educativos que permita comprender el papel funcional de los insectos en los ecosistemas como la polinización, la descomposición y el control biológico.

Así mismo Delors, (1996), manifiesta que la educación ha dejado de constituirse en una alternativa estrictamente pedagógica, para convertirse en una verdadera respuesta a los múltiples problemas que afectan a la comunidad en general, en este caso con contribuciones al conocimiento de especies no carismáticas.

Con respecto a los resultados del segundo instrumento, los estudiantes consideraron que los animales con mayor peligro de extinción se encuentran dentro de las categorías de animales silvestres como es el caso de los osos, monos, tigres, halcones. Animales que son amenazados por el calentamiento global y por la destrucción de hábitats.

En este segundo instrumento, se observa que, la categoría de los insectos no es muy conocida por los estudiantes y por tal razón son muy pocos los niños(as) que 
Memorias del VII Encuentro Nacional de Experiencias en la Enseñanza de la Biologia y la Educación Ambiental y II Congreso Nacional de Investigación en la Enseñanza de la Biología

tienen la percepción de que especies como las mariposas, mariquitas o grillos entre otros se pueden extinguir.

Lo anterior indica que para los participantes, los insectos son considerados como menos llamativos, repugnantes y que son transmisores de enfermedades, como es el caso de los moscos y zancudos, por tal razón no se deberían preservar porque no son importantes. Sin embargo New, TR (2011) en términos éticos, un escarabajo o mosca pueden ser tan necesitados de atención como un tigre o un elefante. Estas percepciones del grupo participante acerca de los insectos, hacen que sean considerados como especies no carismáticas. Una percepción sesgada del mundo de los insectos según Snaddon y Turner (2007) puede reducir los fondos disponibles

para la conservación de los insectos.

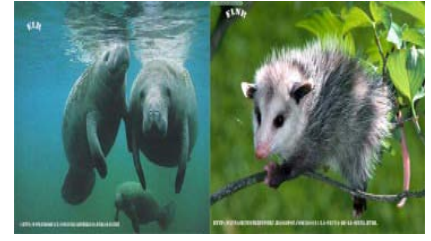

Imagen 1: mamíferos.

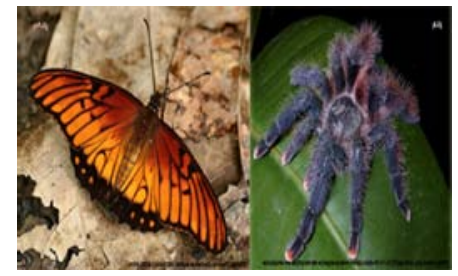

Imagen 3: Invertebrados

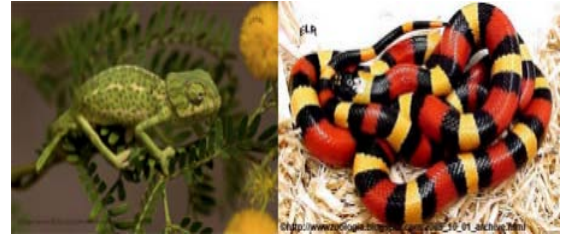

Imágenes 2: reptiles.

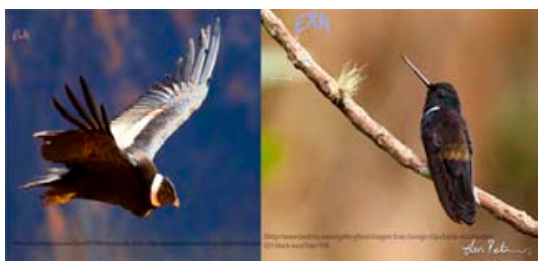

Imagen 4: aves

Respecto a los resultados obtenidos de la presentación en power point en la que los participantes escogen ¿cuál de las dos especies de cada taxón es más agradable y el porqué de la eligen?. Algunas imágenes presentadas fueron:

En esta segunda fase de la prueba de indagación inicial, se tomaron en cuenta estudios como los de Balmford et, al (2002) en el cual, los estudiantes clasificaron diferentes grupos de animales mediante imágenes. En nuestro caso, la clasificación que se le dio estuvo enmarcada en la preferencia de la especie como agradables o desagradables teniendo presente el termino de carismático utilizado por Cracco et, al (2005) que propone generalmente que animales grandes, usualmente mamíferos o aves, más raramente reptiles, peces o 
Memorias del VII Encuentro Nacional de Experiencias en la Enseñanza de la Biología y la Educación Ambiental y II Congreso Nacional de Investigación en la Enseñanza de la Biología

invertebrados, que por su belleza, tamaño, significado simbólico o cultural y resultan agradables al público.

Al ir observando las fichas por medio de la herramienta de la presentación en Power Point, se obtuvieron las siguientes respuestas para cada una de las imágenes: en la imagen 1: mamíferos, escogieron al manatí como especie agradable y no a la zarigüeya debido a debido a que la zarigüeya les recordaba a las ratas. En la imagen 2: reptiles, seleccionaron al camaleón como agradable puesto que para ellos la serpiente es atemorizante y muerde. Para la imagen 3: anfibios, prefirieron la rana como especie agradable debido al color rojo de sus ojos. La imagen 4: aves, tanto el cóndor como el colibrí fueron clasificadas como agradables. Finalizando con la imagen 5: artrópodos, la tarántula en relación con la mariposa fue vinculada como desagradable por algunos de sus caracteres morfológicos como tamaño, extremidades y pelos.

De lo anterior, se resalta que algunos grupos que tienden a ser más llamativos entre los niños(as) son aquellos que clasificaron como carismáticos y que tienen rasgos estéticos atrayentes. A diferencia los grupos clasificados como no carismáticos son aquellos que para ellos constituyen peligro y que estéticamente no son atractivas como el caso de la serpiente y la tarántula de las imágenes 2 y 5 respectivamente.

\section{Conclusiones}

De los resultados obtenidos en el colegio INEM Carlos Arturo Torres, de Tunja, sobre las percepciones de los niños de primaria acerca de las especies carismáticas y no carismáticas se concluye lo siguiente:

Según Kellert (1993) la hipótesis de la biofilia tienen un lineamiento ligado a la influencia del mundo natural en lo estético, e incluso al desarrollo emocional, y espiritual. En este sentido, se hace visible que las especies denominadas carismáticas tienen propiedades estéticas que pueden generan en los niños(as) actitudes y aptitudes de conservación y cuidado del ambiente. Por ese motivo estas especies de acuerdo a Fleishman y Murphy (2009) juegan un rol crítico en el nexo entre la ciencia y la acción ambiental que permitan asumir conciencia acerca de los bienes y servicios de los ecosistemas y el valor de la biodiversidad.

En el desarrollo del taller las especies vinculadas al grupo de los artrópodos fueron catalogadas como menos agradables en comparación a las especies del grupo de los vertebrados. Con relación, al direccionamiento de la dinámica de las investigaciones para la conservación que manifiesta Dunn (2005) se hace pertinente el reflexionar acerca de los escases de indagación sobre el estudio para la conservación de artrópodos y la vinculación de los niños (as) a este tipo de proyectos de conservación. 
Bio-grafia Escritos sobre la Biologia y su Enseñanza.

Edición Extra-Ordinaria. ISSN 2027-1034 P. p 361-367

Memorias del VII Encuentro Nacional de Experiencias en la Enseñanza de la Biologia y la Educación Ambiental y II Congreso Nacional de Investigación en la Enseñanza de la Biología

\section{Bibliografía}

Balmford, A., Clegg, L., Coulson, T., Taylor, J. (2002). Why conservationists should heed pokémon. Science 295(5564): 2367.

Cacco, Marina; Garcia, Laura; Gonzalez, Enrrique; Rodriguez; Lorena; Quintanillán, Ana. (2005). Importancia Global De La Biodiversidad De Uruguay. Proyecto Fortalecimiento de las Capacidades para la Implementación del Sistema Nacional de Áreas Protegidas de Uruguay DINAMA/PNUD/GEF 2005.

Covas O. (2004). Educación ambiental a partir de tres enfoques: comunitario, sistémico e interdisciplinario. Revista iberoamericana de Educación. 34(2), 1-7.

Carrillo D. (2000) Patrimonio cultural. Su Cuidado y Conservación en el Contexto Urbano. El caso de la Ciudad de Campeche. Disponible en http://www.cnmh.inah.gob.mx/ponencias/540.html

Dunn RR (2005) Modern insect extinctions, the neglected majority. Conservation Biology 19: 1030-1036.

Fleishman, E., \& Murphy, DD (2009). A Realistic Assessment of the Indicator Potential of Butterflies and Other Charismatic Taxonomic Groups. Biología de la conservación, 23 (5), 1109-1116.

Kellert, SR. (1993). La base biológica de los valores humanos de la naturaleza. La hipótesis de la biofilia , 42-69.

Snaddon yTurner (2007). A child's eye view of the insect world: perceptions of insect diversity. Environmental Conservation, 34, pp 33-35.

New, T.R. (2011). Launching and steering flagship Lepidoptera for conservation benefit. Journal of Threatened Taxa 3(6): 1805-1817.

Verissimo, D., MacMillan, DC, \& Smith, RJ (2011). Toward a systematic approach for identifying conservation flagships. Conservation Letters , 4 (1), 1-8.

INFOGRAFIA

http://www.fotofrontera.com/2011/04/osos-panda-enamorados-panda-bearsin.html http://www.imagenesdeposito.com/animales/2948/zoom+mapache.html http://www.inriodulce.com/links/amphibians.html\#manatee http://faunasilvestreenperu.blogspot.com/2010/11/la-fauna-de-la-selva.html. http://www.flickr.com/photos/hermosell/6137894949/ http://www.colarte.com/colarte/foto.asp?idfoto $=193766$ http://www.viajeros.com/fotos/islas-galapagos-6/1152128 
Bio-grafia Escritos sobre la Biología y su Enseñanza.

Edición Extra-Ordinaria. ISSN 2027-1034 P. p 361-367

Memorias del VII Encuentro Nacional de Experiencias en la Enseñanza de la Biología y la Educación Ambiental y II Congreso Nacional de Investigación en la Enseñanza de la Biología 